\title{
Deproximating Tredgold's Approximation
}

\author{
David B. Dooner ${ }^{\mathrm{a}, *}$, Mathijs Vivet ${ }^{\mathrm{b}, \mathrm{c}, \mathrm{d},}$, Domenico Mundo ${ }^{\mathrm{b}}$ \\ ${ }^{\mathrm{a}}$ Department of Mechanical Engineering, University of Puerto Rico at Mayagüez, Mayagüez, Puerto Rico 00681 \\ ${ }^{b}$ Department of Mechanical, Energy, and Management Engineering, University of Calabria, Ponte P. Bucci, 87036 Rende (Italy) \\ ${ }^{\mathrm{c}}$ Siemens Industry Software, Interleuvenlaan 68, B-3000 Leuven, Belgium \\ ${ }^{\mathrm{d}}$ Department of Mechanical Engineering, Katholieke Universiteit Leuven, Celestijnenlaan 300B, B-3001 Heverlee (Leuven), Belgium
}

\begin{abstract}
Presented is Tredgold's Approximation for using an equivalent cylindrical gear with spur teeth to "approximate” a bevel gear with straight teeth. This relation is extended to spiral bevel and hypoid gears by utilizing pitch surface curvature in the direction perpendicular to the gear tooth spiral to establish an equivalent gear. Subsequently, the envelope of a planar gear tooth profile in this perpendicular direction is presented. The envelope of the gear tooth profile is used to determine fully conjugate gear teeth profiles for spatial gear elements. This procedure is valid for any tooth profile along with circular and non-circular gears. To validate the methodology, a virtual model of a bevel gear pair ("presented model") is created and an unloaded tooth contact analysis is performed. The procedure used to perform the unloaded tooth contact analysis and determine the corresponding unloaded transmission error is based on the concept of ease-off topography. An example of a face-milled bevel gear pair ("literature model") serves as a reference of correctness in determining the ease-off for unloaded contact. To conclude the paper, the obtained ease-off topography and unloaded transmission error of the presented model are calculated and displayed, demonstrating the specification of fully conjugate teeth.
\end{abstract}

Keywords: Tredgold's Approximation, conjugate motion, Ease-off, Transmission Error, and equation of meshing.

\section{Introduction}

A gear pair consists of two (wheeled) bodies in direct contact to facilitate general motion transmission between rotating axes. The part of the wheel where the two bodies are in direct contact is known as the gear tooth. The majority of such scenarios involve uniform motion between parallel axes. When this occurs, the bodies are cylindrical and the gear tooth shape is determined by establishing mathematical relations in a plane perpendicular to the gear axes of rotation. This planar surface is known as the transverse plane for cylindrical gears. The term planar gearing is commonly used when referring to such motion transmission due to the planar mathematical relations used to establish the gear tooth shape.

A generalized gear pair can be used to achieve motion transmission between two skew axes. Cylindrically shaped wheeled bodies results when the two rotation axes are parallel. Conically shaped wheeled bodies result when the two rotation axes intersect. Lastly, hyperboloidally shaped wheeled bodies result when the two rotation axes are not parallel nor intersect. These hyperboloidally shaped wheels degenerate into cylinders for motion transmission between parallel axes and cones for motion transmission between intersecting axes. The specification of two surfaces in direct contact that ensure $100 \%$ perfect motion transmission between skew axes has been a goal of many researchers and no known methodology exists to singly determine the geometry of two such conjugate surfaces.

Gear tooth shape for cylindrically shaped wheeled bodies has been researched for centuries and research in this area continues today, especially with micro-geometry and tooth profile modifications. The premises for determining conjugate gear teeth is to mathematically describe its shape and obtain a relation between the gear tooth shape, the line of force between two gear teeth in direct contact and the desired angular displacement ratio between the two axes of rotation. For planar gearing, such a relation is frequently referred to as Euler's law of gearing. This process is used throughout the world today. To the authors' awareness, no known procedure exists that extends this approach to an applicable procedure to include hyperboloidal gears.

\footnotetext{
${ }^{*}$ Corresponding author.

Email address: david.dooner@upr.edu
} 
It is viable to specify the shape of one body (say the input gear tooth) and obtain the shape of its "conjugate” mating (output gear tooth) body that ensures desired motion transmission between skew axes. This process is known as the envelope of one body relative to another. In the gearing community, this process is referred to as the equation of meshing. This methodology differs from the above methodology using Euler's law of gearing to establish conjugate gear teeth geometry. Tooth determination via the Euler's law of gearing approach enables the specification of the gear tooth shape (viz., involute, cycloid, circular-arc, and others) along with path of contact, pressure angle, helix angle, and contact ratio. Knowledge of such features is used to study gears and reduce their costs and size, increase reliability, as well as reduce noise and vibrations. Tooth determination via equation of meshing is the basis in today's face cutting process used to fabricate spiral bevel and hypoid gears. Inherent in this equation of meshing process is the inability to determine conjugate gear teeth independent of each other.

Gear designers have introduced an ease-off function to obtain an appropriate tooth profile modification to achieve conjugate motion for gears produced using a face cutting process. In this case, gear designers iteratively obtain gear tooth geometry by using the equation of meshing and evaluating the loaded tooth contact between the two gears. A limitation of this methodology can be highlighted by recognizing the need to post process such gear elements. Today, it is possible to produce spiral bevel and hypoid gears via contour milling using a 5-axis CNC machine. Interestingly, conjugate gear tooth geometry is typically based on emulating a "successful" face cut gear.

This paper presents the first known methodology that provides gear designers the ability to mathematically specify two gear teeth independent of each other and ensure perfect motion transmission when engaged in mesh. The mathematical model ("presented model") makes use of a special spiral angle on pitch surfaces. The envelope of a planar gear element in a direction perpendicular to the gear tooth spiral is presented to obtain fully conjugate surfaces in direct contact for motion transmission between skew axes. The unloaded transmission error for motion transmission is presented and used in an illustrative example to demonstrate this procedure. The methodology begins by revisiting Tredgold's Approximation.

\section{Tredgold's Approximation}

Tredgold's Approximation is presented in many books on gear design for determining the pitch radius and number of teeth that result in an equivalent "bevel” (conical) gear. Implicit is that the pitch radius and number of teeth are for a spur cylindrical gear element. Cylindrical gears are the simplest and most common of the various gear types (viz., bevel, hypoid, worm, wormwheel, and non-circular). Conjugate tooth action for spur cylindrical gears can be easily described and understood using planar geometry. The exact coordinates for a bevel gear's tooth shape along with its varying thickness require an added level of mathematical detail to properly account for its shape and varying tooth thickness. So, it is common to approximate bevel gears with an equivalent spur cylindrical gear to facilitate design. Quantitative expressions are presented to extend this approximation to include spiral bevel and hypoid gear elements. A historical overview of Tredgold's Approximation can be found in the Appendix.

Tredgold's Approximation was initiated to describe spur bevel gears with involute teeth. Although originally specified for involute teeth, Tredgold's Approximation is applicable to other tooth profiles (viz., cycloid and circular-arc). Radzevich proposed extending Tredgold's Approximation to include “crossed axes" gearing by introducing a sphere centered at the intersection between the generator of the pitch surfaces and the common perpendicular to the two axes of rotation [1]. Radzevich used this sphere to generate an equivalent bevel gear pair and did not consider the spiral angle. Apart from Tredgold's Approximation, Figliolini and Angeles investigated the path of contact for involute bevel gears on the surface of a sphere and contrasted involute teeth to a crown rack with "flat flanked" teeth [2]. Stachel joined Figliolini and Angeles and together they proposed cycloidal teeth for a certain class of spatial gear elements [3]. Part of this work is rooted in involute gears as suggested by Phillips [4]. More recently, the three redirected their effort to a broader class of gear tooth profiles with line contact (vs point contact) by investigating the instantaneous motion of the common generator between two axodes [5].

Depicted in Fig. 1 is a representation of a bevel gear set in mesh. The outer radii $r_{p}$ and $r_{g}$ of the conical axodes are used to define an equivalent spur cylindrical gear set with the same speed ratio. The speed ratio $\mathrm{g}$ for a bevel gear set can be defined accordingly:

$$
\mathrm{g} \equiv \frac{\omega_{\mathrm{o}}}{\omega_{\mathrm{i}}}=\frac{\sin \alpha_{\mathrm{p}}}{\sin \alpha_{\mathrm{g}}}=\frac{\mathrm{N}_{\mathrm{p}}}{\mathrm{N}_{\mathrm{g}}}=\frac{\mathrm{r}_{\mathrm{p}}}{\mathrm{r}_{\mathrm{g}}}=\frac{\mathrm{r}_{\text {eq_p }}}{\mathrm{r}_{\text {eq_g }}} .
$$

The equivalent pitch radii $\mathrm{r}_{\text {eq_p }}$ and $\mathrm{r}_{\text {eq_g }}$ for the cylindrical gear elements are

$$
\begin{aligned}
& r_{\text {eq_p }}=\frac{r_{p}}{\cos \alpha_{p}} \\
& r_{\text {eq_g }}=\frac{r_{g}}{\cos \alpha_{\mathrm{g}}} .
\end{aligned}
$$

These same values for equivalent pitch radii can be obtained applying Meusnier's theorem to the conical axodes. 


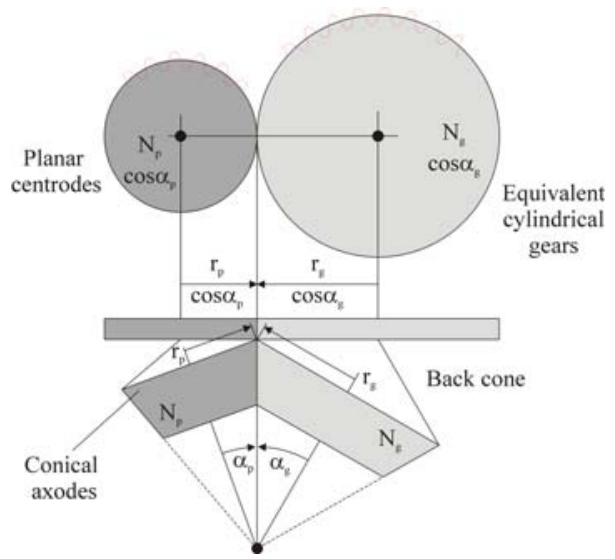

Fig. 1. Tredgold's Approximation.

Tredgold's Approximation uses these equivalent radii to define a pseudo-cylindrical gear pair. These radii are perpendicular to the common generator between two hyperboloidal pitch surfaces. For a constant gear ratio, these pitch surfaces are "circular" where the same hyperbola is defined in the $y-z$ and $x-z$ planes. Below is an equation of a hyperbola

$$
\frac{y^{2}}{b^{2}}-\frac{x^{2}}{a^{2}}=1 \text {, }
$$

where semi-axes $a$ and $b$ are expressed in terms of throat radius $u_{\mathrm{p}}$ and generator angle $\alpha_{\mathrm{p}}$ :

Rearranging Eq. (4) gives

$$
\begin{gathered}
a=\frac{u_{\mathrm{p}}}{\tan \alpha_{\mathrm{p}}} \\
b=u_{\mathrm{p}} .
\end{gathered}
$$

$$
y= \pm \sqrt{u_{\mathrm{p}}^{2}+x^{2} \tan ^{2} \alpha_{\mathrm{p}}}
$$

A plot of $y$ vs $x$ is given in Fig. 2.

The equivalent radius $\mathrm{r}_{\mathrm{eq}}$ for an arbitrary point on the pitch surface is defined as the reciprocal of normal curvature $\kappa_{\mathrm{n}}$. The curvature $\kappa$ for a planar curve can be expressed

$$
\kappa=\frac{y^{\prime \prime}}{\left(1+y^{\prime 2}\right)^{3 / 2}} .
$$

For the planar hyperbola of Eq. (4), the derivatives $y^{\prime}$ and $y^{\prime \prime}$ are

$$
\begin{gathered}
y^{\prime}=\frac{x \tan ^{2} \alpha_{\mathrm{p}}}{\sqrt{u_{\mathrm{p}}^{2}+x^{2} \tan ^{2} \alpha_{\mathrm{p}}}} \\
y^{\prime \prime}=\frac{u_{\mathrm{p}}^{2} \tan ^{2} \alpha_{\mathrm{p}}}{\left[u_{\mathrm{p}}^{2}+x^{2} \tan ^{2} \alpha_{\mathrm{p}}\right]^{3 / 2}} .
\end{gathered}
$$

Substituting the above derivatives $y^{\prime}$ and $y^{\prime \prime}$ into Eq. (5), recognizing $x=w_{\mathrm{p}} \cos \alpha_{\mathrm{p}}$, and specifying the planar curvature $\kappa$ as the maximum pitch surface curvature $\kappa_{\max }$ gives

$$
\kappa_{\max }=\frac{u_{\mathrm{p}}^{2} \sin ^{2} \alpha_{\mathrm{p}} \cos \alpha_{\mathrm{p}}}{\left[u_{\mathrm{p}}^{2} \cos ^{2} \alpha_{\mathrm{p}}+w_{\mathrm{p}}^{2} \sin ^{2} \alpha_{\mathrm{p}}\right]^{3 / 2}} .
$$

Minimum curvature $\kappa_{\min }$ can be expressed (perpendicular to the $x-y$ plane and $y^{\prime}$ )

$$
\kappa_{\text {min }}=-\frac{\cos \alpha_{\mathrm{p}}}{\left[u_{\mathrm{p}}^{2} \cos ^{2} \alpha_{\mathrm{p}}+w_{\mathrm{p}}^{2} \sin ^{2} \alpha_{\mathrm{p}}\right]^{1 / 2}} .
$$




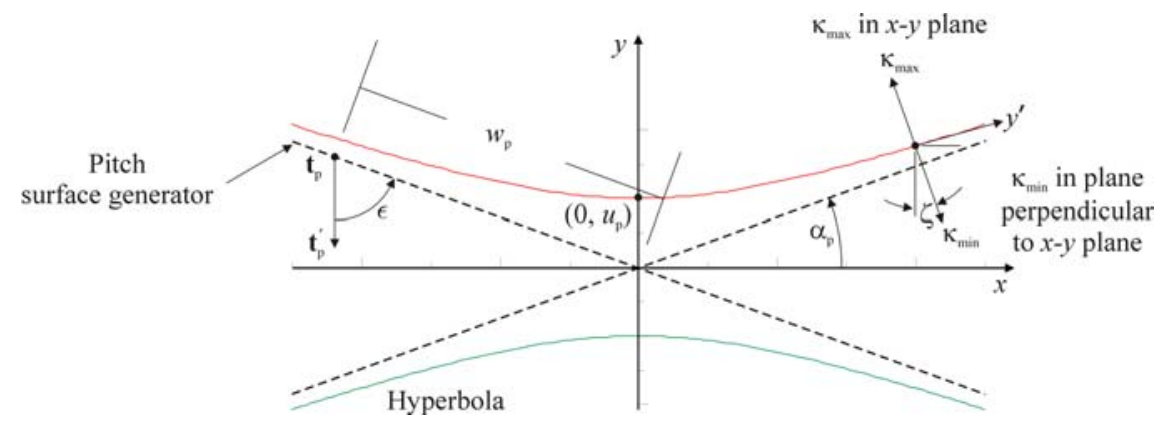

Fig. 2. Plot of hyperbola.

Euler's equation for signed normal surface curvature gives

$$
\kappa_{\mathrm{n}}=\kappa_{\min } \sin ^{2}\left(\epsilon-\psi_{\mathrm{p}}\right)+\kappa_{\max } \cos ^{2}\left(\epsilon-\psi_{\mathrm{p}}\right)
$$

where $\psi_{\mathrm{p}}$ is the instantaneous spiral angle and $\epsilon$ is the angle between a transverse curve and the pitch surface generator as shown if Fig. 2.

$$
\epsilon=\frac{\pi}{2}-\gamma_{\mathrm{p}}=\cos ^{-1}\left(\frac{u_{\mathrm{p}} \sin \alpha_{\mathrm{p}}}{\sqrt{u_{\mathrm{p}}^{2}+w_{\mathrm{p}}^{2} \sin ^{2} \alpha_{\mathrm{p}}}}\right) .
$$

The reciprocal of normal curvature $\kappa_{n}^{-1}$ defines the equivalent radius $r_{\text {eq. }}$. This radius can also be used for cycloid tooth profiles. It is common to use the pitch radius of the mating gear as the diameter of the describing circle when specifying cycloid teeth.

\section{Deproximating Tredgold's Approximation}

The previous section extended Tredgold's Approximation for bevel gear teeth by defining the normal pitch surface curvature in a direction perpendicular to the tooth spiral. Although benign on first glance, this normal pitch surface curvature aligns with the polar plane used in the second law of gearing to decouple spiral angle and pressure angle for general toothed bodies in mesh [6]. As a result, the envelope of a planar tooth profile can be used to define fully conjugate spatial gear teeth in mesh and removal all deviations introduced through Tredgold's Approximation. This procedure of specifying conjugate gear differs from the integrated design and manufacturing process where different gear tooth profiles are specified in terms of a variable diameter cutter [6]. This new procedure separates the gear element from the cutter element and specifies the gear tooth profile directly without considering the manufacturing process. Variable diameter cutters can also be specified using this process. A planar rack or tooth profile based on a circular pitch curve can be used provided the spiral angle satisfies the second law of gearing. Additionally, this procedure is applicable to any tooth profile; namely, involute, cycloidal, or circular-arc.

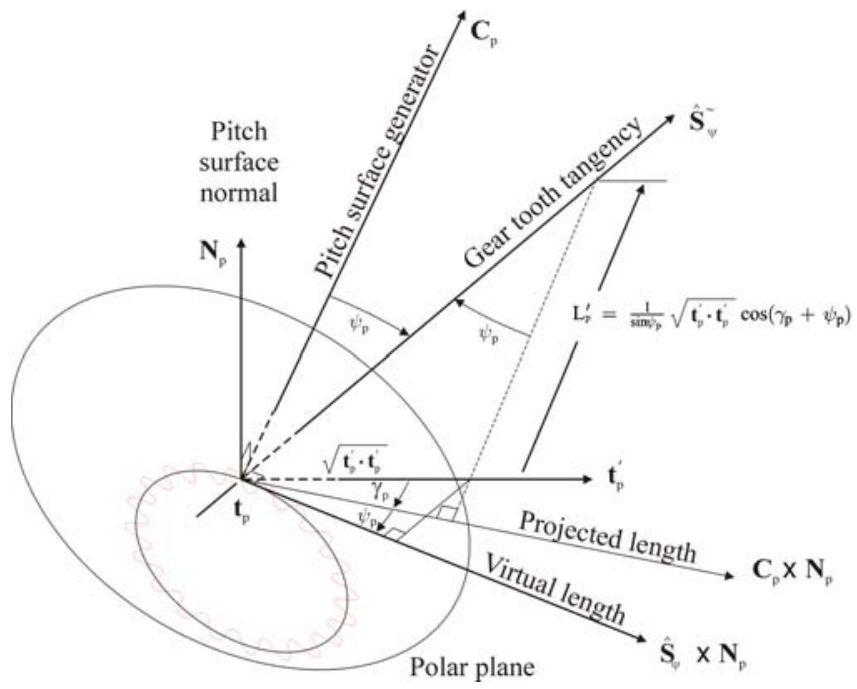

Fig. 3. Tangent plane. 


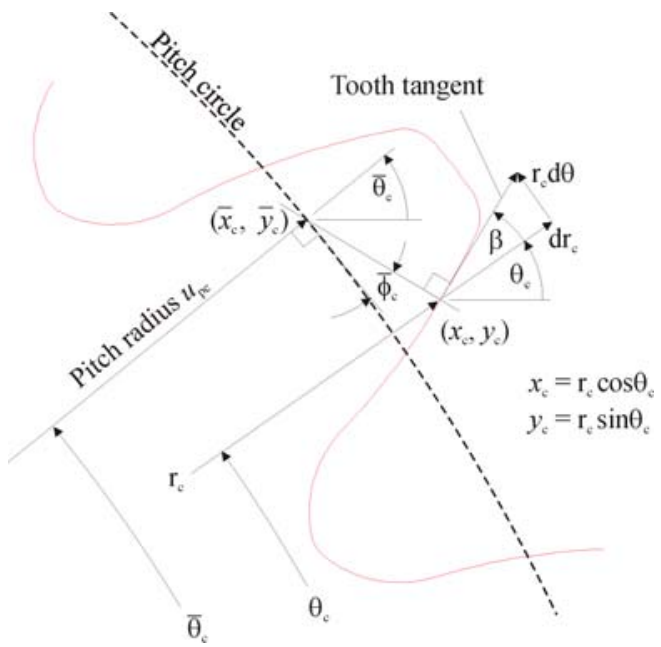

Fig. 4. Normal section of tooth profile.

A system of Cylindroidal coordinates was proposed to describe the kinematic geometry of meshing gear teeth [6]. Fundamental to meshing gear teeth is the ISA or Instantaneous Screw Axis defined by the input gear axis of rotation, the output gear axis of rotation, and the gear ratio. As part of this generalized methodology, a linear line complex defined by the ISA was used to establish the spiral angle on the hyperboloidal pitch surfaces [6]. For an arbitrary point $\mathbf{t}_{\mathrm{p}}$ on the pitch surface, the polar plane associated with this point is perpendicular to the gear tooth surface and the tooth spiral tangency $\mathbb{S}_{\psi}$. Depicted in Fig. 3 is a polar plane, a pitch surface generator direction $\mathbf{C}_{\mathrm{p}}$, an instantaneous spiral angle $\psi_{\mathrm{p}}$, the lead $\mathbf{L}_{\mathrm{p}}^{\prime}$, and a pitch surface normal $\mathbf{N}_{\mathrm{p}}$. Embedded in this polar plane is a planar gear element. The salient feature of this polar plane is that any line of force (i.e., $0^{\circ} \leq \phi \leq 360^{\circ}$ ) ensures reciprocity. Namely, that any two teeth in direct contact will result in the desired instantaneous speed ratio between the two gear rotation axes. The equation of meshing will be used to determine the tooth profile conjugate to the planar gear element. This process is performed twice; once for the input gear (pinion) and once for the output gear (ring gear).

This de-coupling of pressure angle and spiral angle is the key feature that enables the rotation of a planar gear tooth profile relative to a general pitch surface to obtain mating tooth profiles that result in the desired gear ratio (i.e., conjugacy). Depicted in Fig. 4 is a normal section of a planar gear tooth. The profile illustrated is a standard involute profile with $20^{\circ}$ pressure angle. Shown are the coordinates $\left(x_{\mathrm{c}}, y_{\mathrm{c}}\right)$ for an arbitrary point on the tooth profile. The polar coordinates for this point are $\left(\mathrm{r}_{\mathrm{c}}, \theta_{\mathrm{c}}\right)$ where $\mathrm{r}_{\mathrm{c}}$ is the distance from $\left(x_{\mathrm{c}}, y_{\mathrm{c}}\right)$ to the origin and $\theta$ is the angle relative to the $x$-direction. The envelope of $\left(x_{\mathrm{c}}, y_{\mathrm{c}}\right)$ is obtained by determining the image point $\left(\bar{x}_{\mathrm{c}}, \bar{y}_{\mathrm{c}}\right)$ where the line perpendicular to the tooth surface (viz., the line of force) intersects the pitch circle. The polar coordinates of the point $\left(\bar{x}_{\mathrm{c}}, \bar{y}_{\mathrm{c}}\right)$ are $\left(u_{\mathrm{pc}}, \bar{\theta}_{\mathrm{c}}\right)$ where $u_{\mathrm{pc}}$ is the radius of the pitch circle $\left(u_{\mathrm{pc}}\right.$ $=$ constant).

Determination of conjugate tooth profiles depend on $\bar{\theta}_{\mathrm{c}}$. The angle $\bar{\theta}_{\mathrm{c}}$ is obtained using the following relation:

$$
\tan \left[\left(\theta_{\mathrm{c}}+\beta\right)+\frac{\pi}{2}\right]=\frac{\Delta y}{\Delta x}=\frac{u_{\mathrm{pc}} \sin \bar{\theta}_{\mathrm{c}}-y_{\mathrm{c}}}{u_{\mathrm{pc}} \cos \bar{\theta}_{\mathrm{c}}-x_{\mathrm{c}}},
$$

where the angle $\beta$ depends on the tangent to the gear tooth as shown in Fig. 4:

$$
\tan \beta=\frac{\mathrm{r}_{\mathrm{c}} \mathrm{d} \theta}{\mathrm{dr}_{\mathrm{c}}}=\frac{\mathrm{r}_{\mathrm{c}}}{\mathrm{r}_{\mathrm{c}}^{\prime}}
$$

Expanding the above relation for the angle $\bar{\theta}_{\mathrm{c}}$ gives

$$
\mathrm{A} \sin \bar{\theta}_{\mathrm{C}}+\mathrm{B} \cos \bar{\theta}_{\mathrm{C}}+\mathrm{C}=0,
$$

where

$$
\begin{gathered}
\mathrm{A}=\left(\mathrm{r}_{\mathrm{c}}^{\prime} \sin \theta_{\mathrm{c}}+\mathrm{r}_{\mathrm{c}} \cos \theta_{\mathrm{c}}\right)=y_{\mathrm{c}}^{\prime}, \\
\mathrm{B}=\left(\mathrm{r}_{\mathrm{c}}^{\prime} \cos \theta_{\mathrm{c}}-\mathrm{r}_{\mathrm{c}} \sin \theta_{\mathrm{c}}\right)=x_{\mathrm{c}}^{\prime}, \\
\mathrm{C}=-\left[\left(\frac{y_{\mathrm{c}}}{u_{\mathrm{pc}}}\right) \mathrm{A}+\left(\frac{x_{\mathrm{c}}}{u_{\mathrm{pc}}}\right) \mathrm{B}\right] .
\end{gathered}
$$




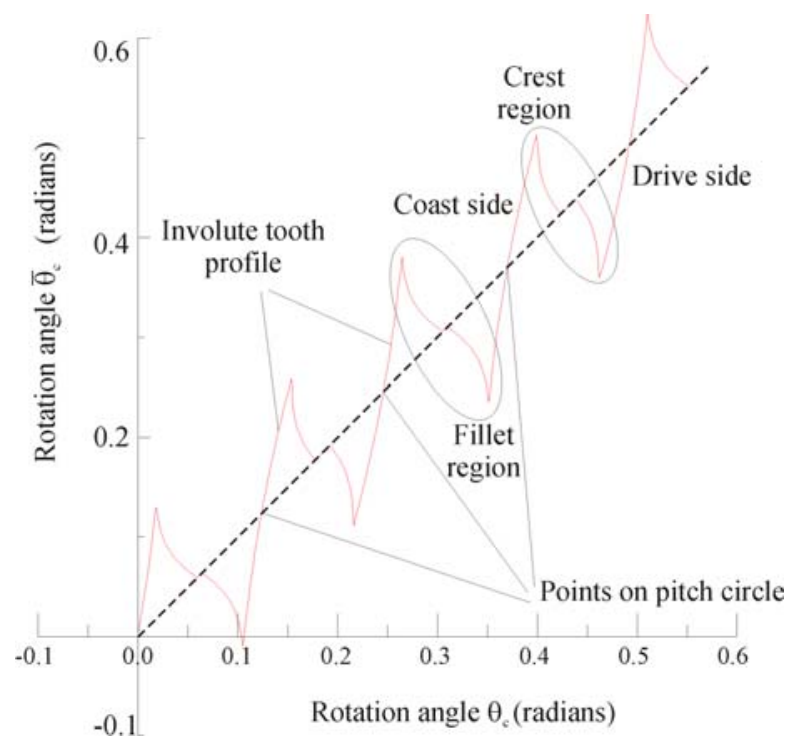

Fig. 5. Relation between $\theta_{\mathrm{c}}$ and $\bar{\theta}_{\mathrm{c}}$.

Solving for the angle $\bar{\theta}_{\mathrm{c}}$ yields

$$
\bar{\theta}_{\mathrm{C}}=\sin ^{-1}\left(\frac{-\mathrm{C}}{\sqrt{\mathrm{A}^{2}+\mathrm{B}^{2}}}\right)-\tan ^{-1}\left(\frac{\mathrm{B}}{\mathrm{A}}\right) .
$$

$\bar{\theta}_{\mathrm{c}}$ oscillates about $\theta_{\mathrm{c}}$ as $\theta_{\mathrm{c}}$ increases monotonically as illustrated in Fig. 6 . Namely, $\bar{\theta}_{\mathrm{c}}$ can be greater than, less than, or equal to $\theta_{c}$. As a result, added attention is warranted when determining $\bar{\theta}_{c}$. The relation between cutter rotation angle $\theta_{\mathrm{c}}$ and gear rotation angle $v_{\mathrm{i}}$ is based on the following equivalence of virtual lengths (instantaneous invariants between ruled surfaces) [6]:

$$
u_{\mathrm{pc}} \bar{\theta}_{\mathrm{c}}=\sqrt{\mathbf{t}_{\mathrm{p}}^{\prime} \cdot \mathbf{t}_{\mathrm{p}}^{\prime}} \cos \left(\gamma_{\mathrm{p}}+\psi_{\mathrm{p}}\right) v_{\mathrm{i}}
$$

For gears with constant speed ratio g (i.e., circulars gears),

$$
\sqrt{\mathbf{t}_{\mathrm{p}}^{\prime} \cdot \mathbf{t}_{\mathrm{p}}^{\prime}}=\sqrt{u_{\mathrm{p}}^{2}+w_{\mathrm{p}}^{2} \sin ^{2} \alpha_{\mathrm{p}}}
$$

The instantaneous pressure angle $\bar{\phi}_{\mathrm{c}}$ of the cutter tooth can be expressed

$$
\bar{\phi}_{\mathrm{c}}=\left(\theta_{\mathrm{c}}-\bar{\theta}_{\mathrm{c}}\right)+\beta \text {. }
$$

Fig. 4 is expanded as illustrated in Fig. 6. The distance $\Delta_{\mathrm{c}}$ between the points $\left(x_{\mathrm{c}}, y_{\mathrm{c}}\right)$ and $\left(\bar{x}_{\mathrm{c}}, \bar{y}_{\mathrm{c}}\right)$ is

$$
\Delta_{\mathrm{c}}= \pm \sqrt{\left(u_{\mathrm{pc}} \cos \bar{\theta}_{\mathrm{c}}-x_{\mathrm{c}}\right)^{2}+\left(u_{\mathrm{pc}} \sin \bar{\theta}_{\mathrm{c}}-y_{\mathrm{c}}\right)^{2}}
$$

Note that $\Delta_{\mathrm{c}}$ changes \pm sign between dedendum and addendum.

Each angular position $\theta_{c}$ of the planar tooth profile defines an image angle $\bar{\theta}_{\mathrm{c}}$, an instantaneous pressure angle $\bar{\phi}_{\mathrm{c}}$, a distance $\Delta_{\mathrm{c}}$, along with the corresponding angular position $v_{\mathrm{i}}$ of the gear element. At last, the Cartesian coordinates of a conjugate profile trace are presented. These traces define the gear tooth surface. A line perpendicular to the tooth surface satisfies the first law of gearing [6]. Such coordinates depend on a general point $\mathbf{t}_{\mathrm{p}}$ on the hyperboloidal pitch surface along with the surface normal $\mathbf{N}_{\mathrm{p}}$ and the spiral tangency $\mathbb{S}_{\psi}$ coincident with $\mathbf{t}_{\mathrm{p}}$. The spatial coordinates $\Gamma$ of the gear tooth trace (envelope of planar points $x_{\mathrm{c}}$ and $y_{\mathrm{c}}$ ) are

$$
\Gamma=\mathbf{t}_{\mathrm{p}}+\Delta_{\mathrm{c}}\left[\left(\mathbb{S}_{\psi} \times \mathbf{N}_{\mathrm{p}}\right) \cos \bar{\phi}_{\mathrm{c}}+\mathbf{N}_{\mathrm{p}} \sin \bar{\phi}_{\mathrm{c}}\right]
$$

Using Eq. (17) to describe gear teeth, the orientation of the polar plane changes as the angular position $v_{\mathrm{i}}$ increases. As a result, a zigzag trace results due to this change in orientation for each angular position $\theta$ as illustrated in Fig. 7 . The zigzag data trace is interpolated and re-sampled to yield a smooth transverse profile (intersection between tooth profile and transverse surface). This procedure is applicable to circular and non-circular gears. Non-circular gears utilize a varying lead to maintain a constant spiral angle for each transverse section. For bevel gears, the net spiral angle decreases as the axial position of contact decreases. 


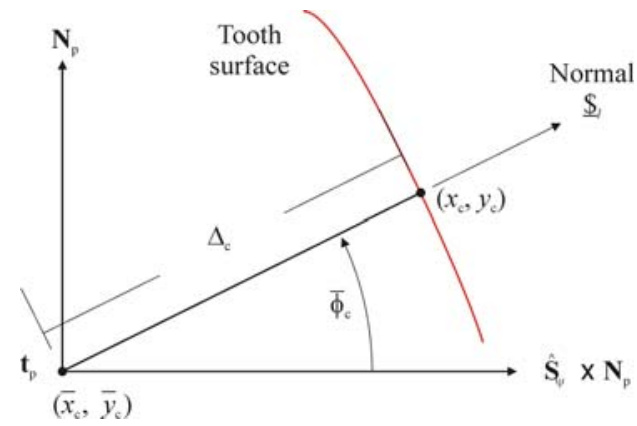

Fig. 6. Tooth pressure angle (polar plane).

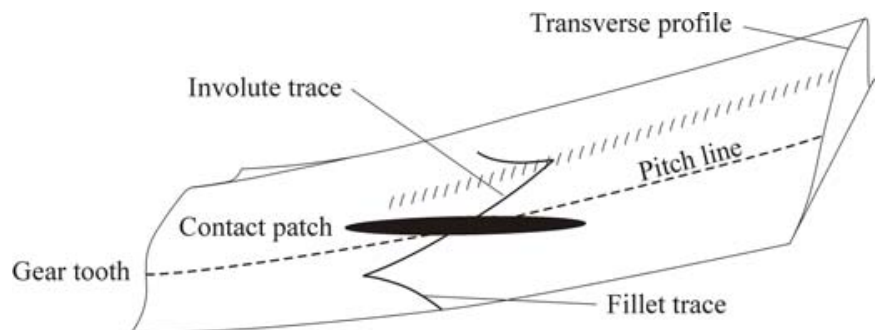

Fig. 7. Trace of conjugate points on tooth surface.

\section{An ease-off based method for unloaded tooth contact analysis}

Using the above described methodology, a virtual model of a bevel gear pair ("presented model”) is created and analyzed in Section 5. To prove the validity of the methodology, this means that the designed gear and pinion flanks are conjugate from the start, it was opted to analyze the gear pair using the well-known technique of unloaded tooth contact analysis. The assessment of the obtained flanks is performed using an ease-off based method for unloaded tooth contact analysis. It is important to note that this technique is fundamentally different from the procedure for spatial gearing that has been developed in the previous sections. The used procedure to obtain the unloaded tooth contact analysis and corresponding unloaded transmission error curves are presented in the following section. To provide the reader with a reference for correctness of the UTCA method, the results obtained for a "classic" bevel gear pair ("literature model") are briefly discussed at the end of this section.

Today, hypoid and bevel gears are typically designed by simulating the manufacturing process in order to determine the machine settings and cutter specifications [7]. Unloaded tooth contact analysis (UTCA) is usually performed to obtain desired characteristics for transmission error curve and contact patterns along the tooth surfaces. One method for UTCA is described in detail by Litvin et al. in [8, 9]. In essence, this UTCA method identifies the contact points as the points on the pinion and gear flanks for which the position vectors are coincident and their normal vectors are collinear, for a given rotation of the pinion and the gear. The contact points are therefore found by numerically solving a system of nonlinear equations. To improve the calculation efficiency and overcome some numerical problems, intrinsic to this method for tooth contact analysis (TCA), Bär [11] and Kolivand [7, 10] proposed an ease-off topography based methodology for TCA.

Recently, the concept of ease-off based TCA has been used by other researchers in order to analyze or optimize a given hypoid or bevel gear pair. Kolivand [12] uses the approach to analyze the gear mesh efficiency of hypoid gear pairs. Park [13] formulates a methodology to calculate surface wear of hypoid gear teeth for which the contact loads on the gear flanks are estimated, using an ease-off based TCA method. Shih [14] uses the concept of ease-off to modify the tooth profiles so that the ease-off topography matches a predefined transmission error along the contact path and a desired bearing ratio along the contact line. In the above studies a gear based ease-off formulation is used, which means that the ease-off topography was defined as the deviation of the real gear surface from the conjugate gear surface (the theoretical, conjugate to the mating pinion). Artoni [15] uses a pinion based ease-off approach to define the required corrective actions that needs to be applied on the pinion so that the contact properties of the whole gear pair match with a predefined transmission error.

\subsection{The conjugate surface to the pinion tooth flank}

In this paper the concept of gear based ease-off is used to calculate the deviation of the real gear tooth flank from the conjugate gear. The conjugate gear is obtained by solving the equation of meshing between the real pinion (also referred to as the input gear) and its to-be-computed theoretical conjugate.

Consider a gear pair for which the pinion flank is expressed in the Pinion Reference Frame $S_{1}$, while the gear and conjugate gear flank are given in the Gear Reference Frame $S_{2}$. The Housing Reference Frame $S_{h}$ is used to describe the relative 
orientation between the pinion and the gear. Fig. 8 shows the Pinion Reference Frame and the Gear Reference Frame, for an assembled gear pair. Note that Fig. 8 also includes the shaft offset, or hypoid offset between the gear and pinion rotational axes. When the designed shaft offset $E$ is non-zero, the gear pair is considered to be a hypoid gear pair. In case of zero shaft offset (intersecting rotational axes), the gear pair is a bevel gear pair. Since the pinion and gear are installed without the presence of misalignments, the Housing and the Pinion Reference Frame are identical for the pinion roll angle $\eta_{1}=0$. The shaft angle $\Sigma$ defines the angle between the pinion rotation axis $z_{1}$ and the gear rotation axis $z_{2}$.

For every point on the pinion flank the Cartesian coordinate vector $\mathbf{r}_{1}^{(1)}$ and the corresponding surface normal $\mathbf{N}_{1}^{(1)}$ are considered to be known and expressed in $S_{1}$. This makes it convenient to formulate the equation of meshing between the pinion and the gear, using the Engineering Approach [8, 9].

It is known from Differential Geometry that the equation of meshing determines the envelope to a family of surfaces. This family of surfaces is created by the pinion as it rotates around its axis, represented by the pinion roll angle $\eta_{1}$. The envelope to the family of surfaces is found by determining the pinion roll angle $\eta_{1}$ for every point on the pinion surface that satisfies following scalar equation, written in the Housing Frame:

$$
\mathbf{N}_{h}^{(1)} \cdot \mathbf{v}_{h}^{(12)}=0
$$

Here $\mathbf{v}_{h}^{(12)}$ resembles the relative velocity between a point on surface 1 and a point on surface 2 that is coincident to surface 1 . The pinion surface normal at the point on surface 1, is given by $\mathbf{N}_{h}^{(1)}$. The equation of meshing as written in Eq. (18), states that the envelope to the generated family of pinion surfaces is found by solving for the value of pinion roll angle for every point $P$ so that the scalar product between the relative velocity $\mathbf{v}_{h}^{(12)}$ and the surface normal vector $\mathbf{N}_{h}^{(1)}$ is zero. The relative velocity directly defines the correct kinematic relationship between pinion and gear. If the (hypoid) gear pair is installed without the presence of misalignments, Eq. (18) can be written in the following form:

$$
\mathbf{N}_{h}^{(1)} \cdot\left[\left(\boldsymbol{\omega}_{h}^{(1)} \times \mathbf{r}_{h}^{(1)}\right)-\left(\boldsymbol{\omega}_{h}^{(2)} \times \boldsymbol{\rho}_{h}\right)\right]=0 .
$$

In Eq. (19) $\boldsymbol{\rho}_{h}$ is written as $\boldsymbol{\rho}_{h}=\mathbf{r}_{h}^{(1)}-\mathbf{E}_{h}$ to account for the rotational vector moment that arises due the non-zero hypoid offset $E$, represented by the vector $\mathbf{E}_{h}$, in the Housing Frame. To obtain an expression in the Housing Frame $S_{h}$ for the coordinate vector of the points on the pinion $\mathbf{r}_{h}^{(1)}$ and their surface normal vectors $\mathbf{N}_{h}^{(1)}$ the following coordinate transformation can be used:

$$
\mathbf{M}_{h 1}=\left[\begin{array}{cccc}
\cos \left(\eta_{1}\right) & \sin \left(\eta_{1}\right) & 0 & 0 \\
-\sin \left(\eta_{1}\right) & \cos \left(\eta_{1}\right) & 0 & 0 \\
0 & 0 & 1 & 0 \\
0 & 0 & 0 & 1
\end{array}\right]
$$

$$
\mathbf{r}_{h}^{(1)}=\mathbf{L}_{h 1}\left(\eta_{1}\right) \mathbf{r}_{1}^{(1)}
$$

$$
\mathbf{N}_{h}^{(1)}=\mathbf{L}_{h 1}\left(\eta_{1}\right) \mathbf{N}_{1}^{(1)}
$$

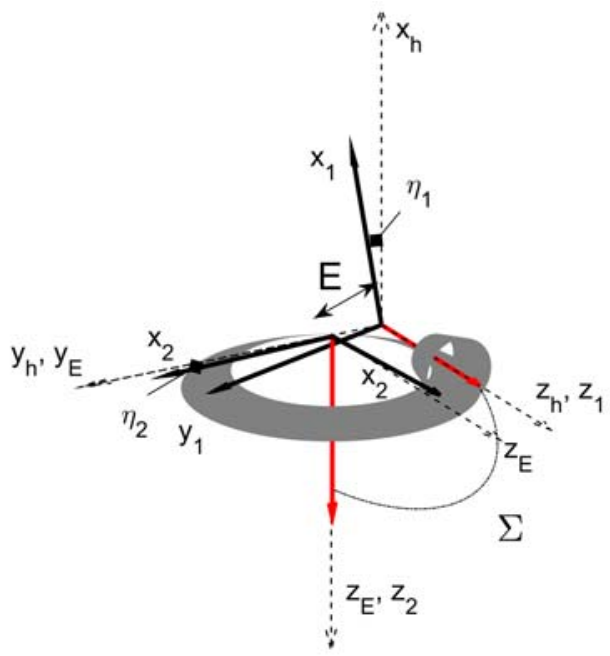

Fig. 8. The Pinion Reference frames $S_{1}$ and the Gear Reference Frame $S_{2}$ as they are positioned in space when the gear pair is assembled. The angle between the pinion rotation axis $z_{1}$ and the gear rotation axis $z_{2}$ is defined as the shaft angle $\Sigma$. The distance between the gear and pinion rotational axes, is given by the shaft offset $E$. 
The rotational matrix $\mathbf{L}_{h 1}$ that is used in Eq. (21) and Eq. (22) is the rotational component of the homogeneous transformation matrix $\mathbf{M}_{h 1}$ from Eq. (20). An expression for the angular rotational vectors $\boldsymbol{\omega}_{h}^{(1)}$ and $\boldsymbol{\omega}_{h}^{(2)}$ for the pinion and the gear respectively, is given by:

$$
\begin{gathered}
\boldsymbol{\omega}_{h}^{(1)}=\left[\begin{array}{c}
0 \\
0 \\
\omega^{(1)}
\end{array}\right] \\
\boldsymbol{\omega}_{h}^{(2)}=\mathbf{L}_{h 2_{E}}\left[\begin{array}{c}
0 \\
0 \\
-\omega^{(2)}
\end{array}\right] .
\end{gathered}
$$

The rotation matrix $\mathbf{L}_{h 2_{E}}$ of Eq. (24) is again the rotational component of the homogeneous transformation matrix $\mathbf{M}_{h 2_{E}}$ from Eq. (25), where for a bevel gear pair the shaft offset $E=0 \mathrm{~mm}$.

$$
\mathbf{M}_{h 2_{E}}=\left[\begin{array}{cccc}
\cos (\Sigma) & 0 & -\sin (\Sigma) & 0 \\
0 & 1 & 0 & 0 \\
\sin (\Sigma) & 0 & \cos (\Sigma) & 0 \\
0 & 0 & 0 & 1
\end{array}\right]\left[\begin{array}{llll}
1 & 0 & 0 & 0 \\
0 & 1 & 0 & E \\
0 & 0 & 1 & 0 \\
0 & 0 & 0 & 1
\end{array}\right] .
$$

The magnitude of the angular rotation of the (conjugate) gear is defined by the gear ratio $m_{21}$, given in Eq. (26). In this equation $Z_{1}$ and $Z_{2}$ correspond to the number of the teeth of the pinion and the gear, respectively.

$$
m_{21}=\frac{\omega^{(2)}}{\omega^{(1)}}=\frac{Z_{1}}{Z_{2}}
$$

The conjugate gear flank is obtained by solving the equation of meshing for every point on the surface flank to determine a specific value of pinion roll $\eta_{1}$. This value of pinion roll angle $\eta_{1}$, corresponds to the rotation a point of the pinion flank needs to undergo in order to reach the position where it will make contact with the conjugate gear. The set of all these points form the Action Surface, which is similar to the line of action for planar gearing. The conjugate flank is then obtained by transforming the points on the Action Surface [7] to the Gear Reference Frame $S_{2}$. The points on the conjugate gear surface $\mathbf{r}_{2}^{(2 c)}$, are given by following transformation:

$$
\mathbf{r}_{2}^{(2 c)}=\left[\mathbf{M}_{h 2_{E}}\left(\eta_{2}\right) \mathbf{M}_{2_{E} 2}\right]^{-1} \mathbf{M}_{h 1}\left(\eta_{1}\right) \mathbf{r}_{2}^{(1)} .
$$

The homogeneous transformation matrix that is required to complete the transformation from the Housing Frame to the Gear Reference Frame in Eq. (27), is defined as:

$$
\mathbf{M}_{2_{E} 2}=\left[\begin{array}{cccc}
\cos \left(\eta_{2}\right) & -\sin \left(\eta_{2}\right) & 0 & 0 \\
\sin \left(\eta_{2}\right) & \cos \left(\eta_{2}\right) & 0 & 0 \\
0 & 0 & 1 & 0 \\
0 & 0 & 0 & 1
\end{array}\right]
$$

\subsection{Creation of the ease-off surface}

The steps required to obtain the ease-off topography are explained in the following subsections. To illustrate the concepts, a spiral bevel gear pair set ("literature model") is used as a reference case, which was described by Litvin et al. in [8, 9]. The motivation for this is dual; it helps to explain the different concepts better while it allows the reader to reproduce the results of the method. Fig. 9 shows the tooth flank geometry of a face-milled spiral bevel gear and pinion, obtained by simulating the manufacturing process described in $[8,9]$. The blank details of the gear pair are listed in Table 1.

\subsubsection{The projection plane}

To determine how much the real gear flank deviates from the (theoretical) conjugate of its mating flank, the ease-off topography needs to be constructed by performing a point-to- point comparison between points on the real gear flank and points on the calculated conjugate flank. To ease the effort of bookkeeping, it is common practice to project the tooth flank points to a plane that contains the gear rotational axis, the projection plane. The projection is obtained by rotating the flank points ( $x_{2}, y_{2}$, $z_{2}$ ) in $S_{2}$ along a circle arc around the gear rotational axis to the RZ-plane. Fig. 10 visualizes the creation of the projection plane, which can be obtained by using the equations from Eq. (29). 


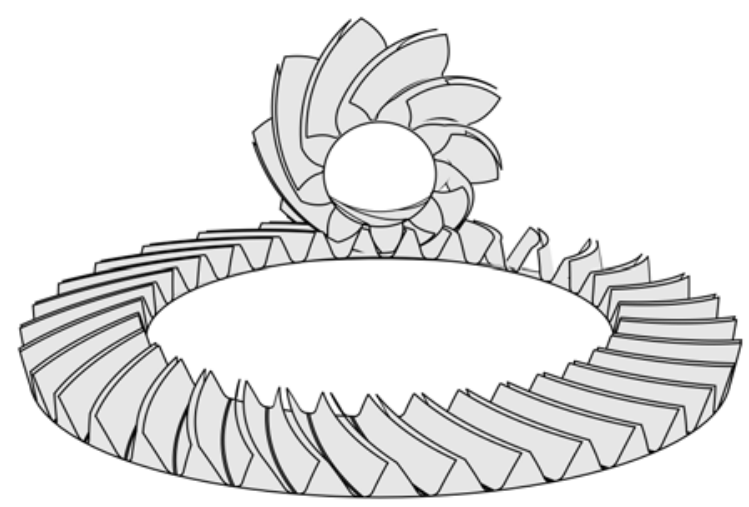

Fig. 9. Spiral bevel gear pair that was created based on the data found in Litvin et al. [8, 9] and is given as reference example.

Table 1. Blank data of the bevel gear pair, described in $[8,9]$.

\begin{tabular}{lcc}
\hline Blank data & Pinion & Gear \\
\hline Number of teeth & \multicolumn{2}{c}{33} \\
Shaft Angle [deg.] & \multicolumn{2}{c}{90.00} \\
Mean Spiral Angle [deg.] & \multicolumn{2}{c}{32.00} \\
Face Width [mm] & \multicolumn{2}{c}{27.50} \\
Mean Cone Distance [mm] & \multicolumn{2}{c}{68.92} \\
Pitch Angle [deg.] & 15.2551 & 74.7449 \\
Root Angle [deg.] & 13.8833 & 69.5833 \\
Face Angle [deg.] & 20.4167 & 76.1167 \\
Clearance [mm] & \multicolumn{2}{c}{1.03} \\
Addendum [mm] & 6.64 & 1.76 \\
Dedendum [mm] & 2.79 & 7.67 \\
Hand of spiral & RH & LH \\
\hline
\end{tabular}

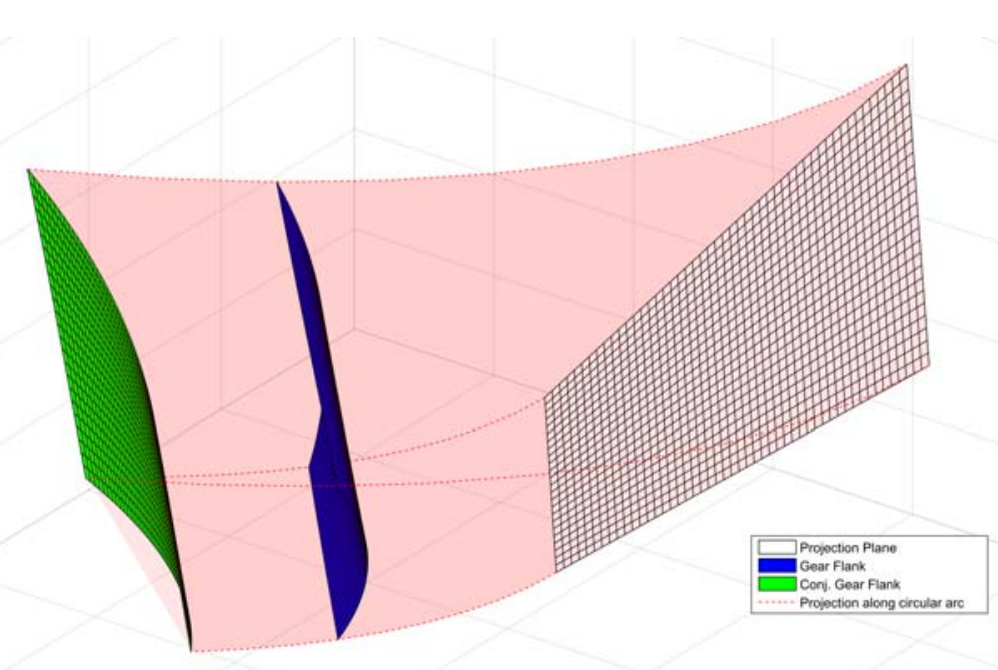

Fig. 10. Points of the gear and conjugate gear flank are projected along a circle arc to create the projection plane. 


$$
R_{\text {proj }}=\sqrt{x_{2}^{2}+y_{2}^{2}} \text { and } \mathrm{Z}_{\text {proj }}=z_{2} \text {. }
$$

The pinion and the gear surface are usually created by specifying machine settings for both pinion and gear. In this case it is not uncommon that the settings result from an optimization process in which TCA is performed to calculate the desired contact patterns. Next to that, the conjugate gear flank is determined as the envelope to the family of pinion surfaces. Therefore a direct point-to-point comparison between real gear points and conjugate gear points is often impossible and interpolation or surface fitting techniques are needed. In the presented method the projection plane is bounded by identifying an area where contact between the pinion and the gear can occur. This area is determined from the overlap of the real gear and the conjugate gear data points in the projection plane. After the boundaries of this area in the projection plane have been defined, a regular grid is applied to the area in order to calculate for each point of the projection plane $\left(R_{\text {proj }}, Z_{\text {proj }}\right)$ the projection angle of the gear and the conjugate gear.

\subsubsection{The ease-off topography}

The ease-off topography can be constructed based on the projection angles of the gear and the conjugate gear. Because the projection angle corresponds to the angle that the point needs to be rotated around the gear axis in order to reach the projection plane, the difference between the gear projection angle $\theta_{\text {gear }}$ and the conjugate gear projection angle $\theta_{\text {conj }}$ directly indicates how much both surfaces deviate from each other. The ease-off topography, for every point on the projection plane, can therefore be written as:

$$
E O_{\text {rad }}=\theta_{\text {gear }}-\theta_{\text {conj }} .
$$

The above formula can also be interpreted as the extra amount of rotation a point on the gear surface would require in order to reach the conjugate flank (and be in contact with the pinion). The ease-off topography can be expressed as an angle or a distance (e.g., $\mu \mathrm{rad}$ or $\mu \mathrm{m}$ ). To obtain the latter, every value of ease-off, belonging to a certain point in the projection plane, needs to be multiplied by its earlier calculated radius. Fig. 11 shows the ease-off topography for the bevel gear pair that is shown in Fig. 9 .

\subsubsection{Unloaded transmission error}

When the ease-off topography is expressed as an angle, the unloaded transmission error can be directly derived from it. In general transmission error is defined as the difference between the rotational angle of the gear and the rotational angle that the gear would have in case of perfect motion transfer. Here perfect motion transfer would require the gear flank to be conjugate and infinitely stiff. This relation is given in Eq. (31). It directly corresponds to the ease-off topography of Eq. (30), as this formula expresses the extra amount of rotation that is required for a point on the gear flank to reach the point on the conjugate gear surface.

$$
\Delta \eta_{2}=\eta_{2}-m_{21} \eta_{1}
$$

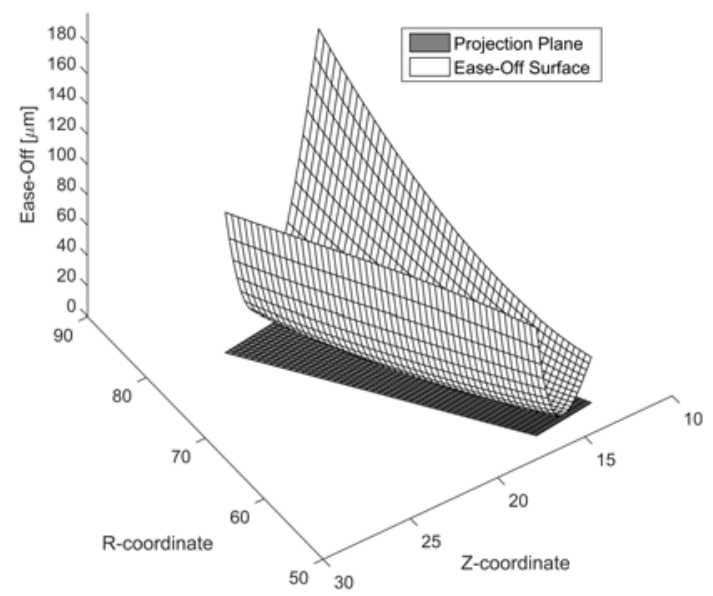

Fig. 11. Ease-off topography for the example, shown in Fig. 9. The ease-off values are calculated in $\mu$ m for all the points of the projection plane. 


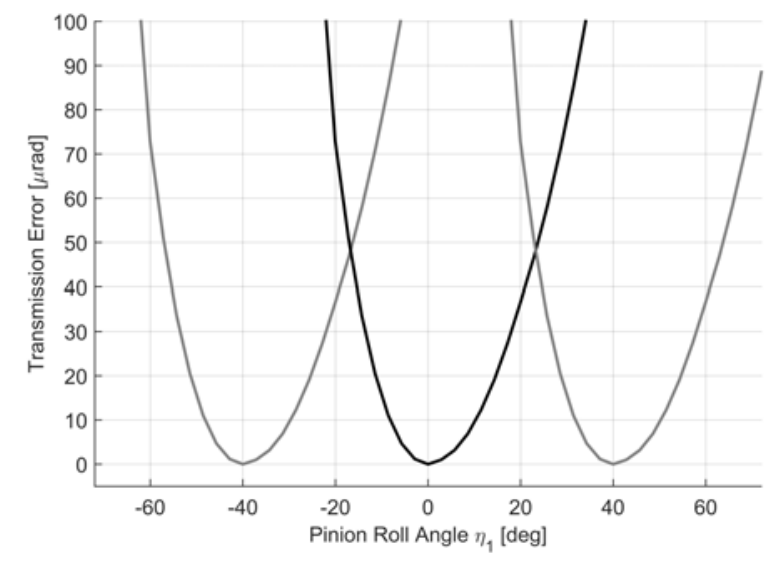

Fig. 12. Unloaded Transmission Error for the spiral bevel gear pair, described in [9].

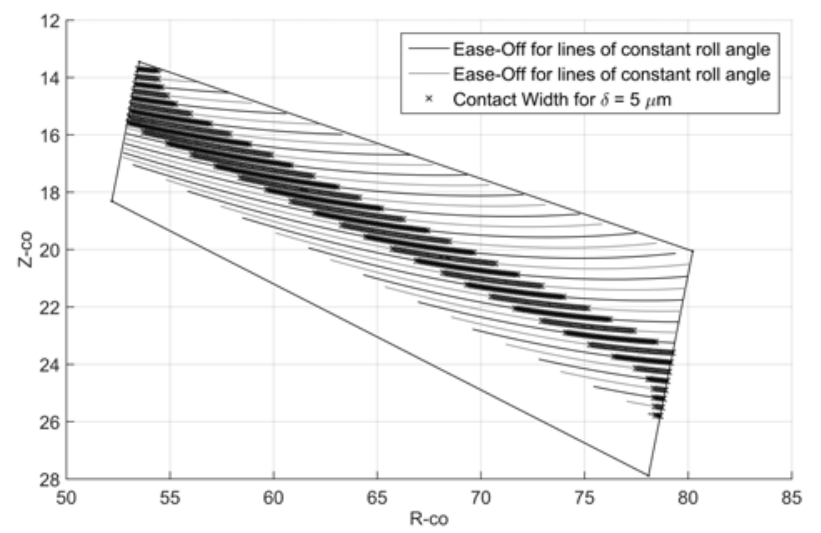

Fig. 13. Contact Points Path (CPP) for the spiral bevel gear pair, described in [9].

The unloaded transmission error curve, from Fig. 12, was obtained by considering a range of pinion roll angle values $\eta_{1}$. For every value of roll angle $\eta_{1}$, points in the projection plane are found that create a line of constant roll angle. The value of roll angle $\eta_{1}$ was earlier determined for every point on the projection plane, when calculating the conjugate gear element. The set of all pinion roll angles $\eta_{1}$ is also referred to as the Surface of Roll Angles, [7].

A line of constant roll angle can be seen as a line that contains all possible contact points for a certain pinion roll angle $\eta_{1}$. Determining which points make contact, is done by calculating the ease-off values that correspond to the points on the line of constant roll angle. The point with the lowest value of ease-off, will be the first point that comes into contact with the pinion. The extra rotation that the gear requires for this, is given by the ease-off value of that point and will be the value of unloaded transmission error for that considered roll angle $\eta_{1}$. In unloaded tooth contact analysis, it is also common to calculate the points that would be in contact if a certain value of separation distance $\delta$ is considered, in order to give an idea of how the contact would spread along a line of roll angle and across the face width of the gear flank. Fig. 13 shows the lines of constant roll angle that were obtained for the bevel gear pair of Table 1. The contact point path (CPP) is obtained by considering all the points (marked by “ $\times$ ”), which have an ease-off value (in $\mu \mathrm{m}$ ) below the separation distance of $\delta=5 \mu \mathrm{m}$. When two teeth flanks are perfectly conjugate with one another, line contact would occur over the complete line of constant roll angle and the CPP marker “ $\times$ ” would cover the complete flank. Considering all the minimum ease-off values along the indicated lines of constant roll angle, allows for the creation of the complete unloaded transmission error curve, which is shown in Fig. 12.

\section{Illustrative Example}

A virtual model of a spiral bevel gear set ("presented model") is created using the methodology presented in Section 3 . The spiral bevel gear was created to resemble the one that was presented in Section 4. A summary of the gear data is presented in Table 2 and a model of the gear pair is depicted in Fig. 14. The shaft center distance for the gear pair is specified to be zero as presented in Table 2. However, using the general methodology for gearing proposed in the Kinematic Geometry of Gearing [6], the spiral bevel gear set is a hypoid gear set where the shaft offset is zero. However, the shaft offset $\mathrm{E}=0.00055 \mathrm{~mm}$ is specified to avoid numerical ill-conditioning. 
An evaluation of the new methodology for describing gear teeth, presented in Section 3, is provided by using the ease-off based methodology for unloaded tooth contact, described in Section 4. Enlarged views of an input gear tooth before and after resampling are provided in Fig. 15. Fig. 16a shows that when the gear pair is assembled as a true bevel gear set $(\mathrm{E}=0 \mathrm{~mm})$, the unloaded tooth contact analysis shows a small increase in the unloaded transmission error as the pinion angle increases. The TE reaches a maximum value of $1.624 \mu$-rad at $31.51^{\circ}$ before the next tooth enters contact. The small increase in TE, as the pinion roll angle increases, can be directly related to the made approximation concerning the shaft angle by looking at the ease-off topography, displayed in Fig. 17a. In case of a shaft offset of $E=0 \mathrm{~mm}$, the ease-off topography shows an increasing value along the face width of the gear. This means that the created tooth flanks are not fully conjugate for the considered installment settings.

When a shaft offset adjustment of $\mathrm{E}=0.00055 \mathrm{~mm}$ is applied, Fig. 17b shows that the ease-off does not increase over the face width of the gear. This means that the conjugate gear flank, which is calculated by taking into account the installments settings, now perfectly matches the designed gear flank around the pitch zone. Since TE and ease-off are directly related, as explained in Section 4, using an offset adjustment of $\mathrm{E}=0.00055 \mathrm{~mm}$, yields zero TE for the designed spiral bevel gear set, given by Fig. 16b. Note also how the axial contact ratio of 1.361 matches with the overlap between TE curves of two teeth, displayed in both images of Fig. 16.

Finally, Tredgold's approximation as presented in Section 2 is used to determine the gear teeth geometry for the gear pair data in Table 2. There is no visual difference between this tooth profile approximation and the exact tooth profile using the methodology of Section 3. A quantitative comparison between these two profiles is presented based on the Euclidean distance between the two profiles; this Euclidean distance is displayed in Fig. 18. As observed in Fig. 18, Tredgold's Approximation is exact only at the pitch point.

Table 2. Gear pair data using the Delgear process $^{1}$.

\begin{tabular}{lcc}
\hline Blank data & Pinion & Gear \\
\hline Number of teeth & 9 & 33 \\
Shaft Angle [deg.] & 90.00 \\
Mean Spiral Angle [deg.] & \multicolumn{2}{c}{32.00} \\
Face Width [mm] & \multicolumn{2}{c}{27.50} \\
Mean Cone Distance [mm] & \multicolumn{2}{c}{68.75} \\
Axial contact ratio [-] & \multicolumn{2}{c}{1.361} \\
Generator Angle [deg.] & $15.255 \quad 74.745$ \\
Tooth Profile [-] & \multicolumn{2}{c}{ Involute } \\
Normal Tooth Module [mm] & \multicolumn{2}{c}{3.409} \\
Addendum [mm] & \multicolumn{2}{c}{2.727} \\
Dedendum [mm] & \multicolumn{2}{c}{2.898} \\
Hand of spiral & LH RH \\
\hline
\end{tabular}

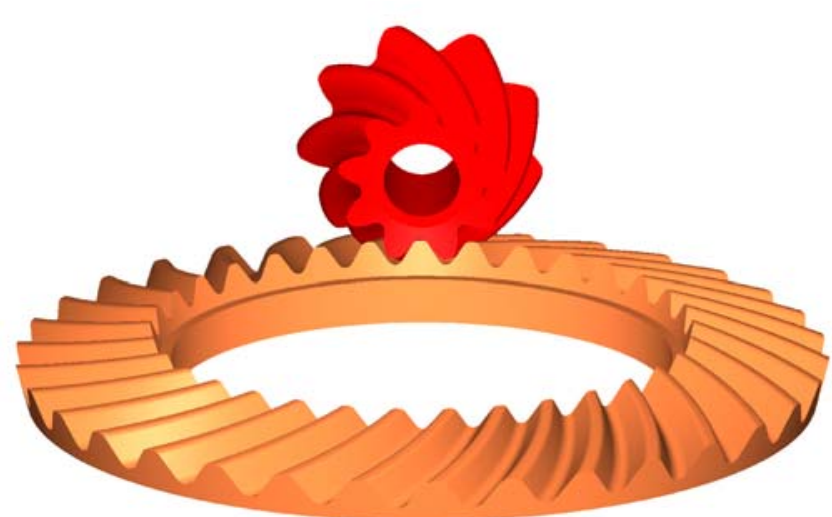

Fig. 14: Gear view.

\footnotetext{
${ }^{1}$ The Delgear process for gear design is based upon fundamental mathematical principles presented in The Kinematic Geometry of Gearing [6]. This process comprises a system of cylindroidal coordinates, three laws of gearing, along with instantaneous invariants between hyperboloidal pitch surfaces (not always axodes). Together, these relations are the basis for the Delgear program [16].
} 

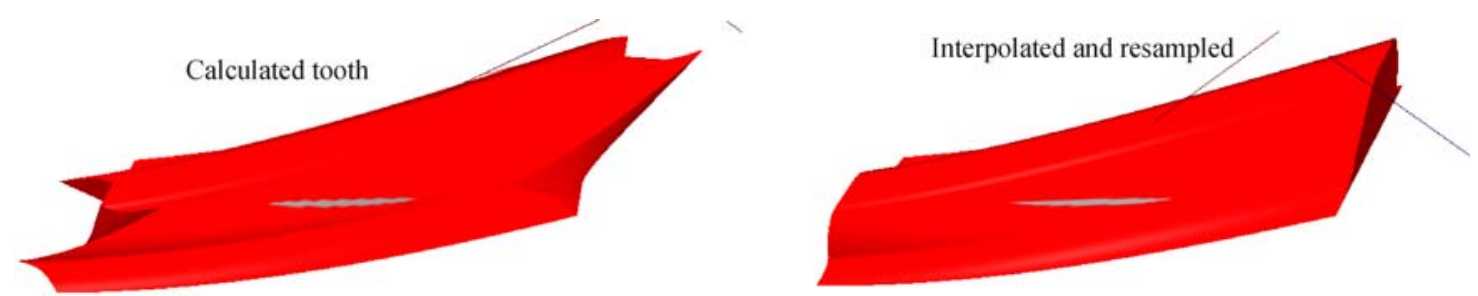

Fig. 15. Input gear teeth with contact pattern.

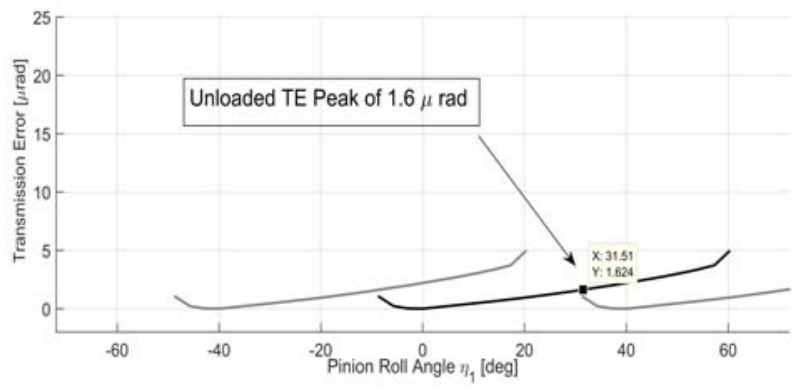

(a) Shaft Offset $\mathrm{E}=0.0 \mathrm{~mm}$.

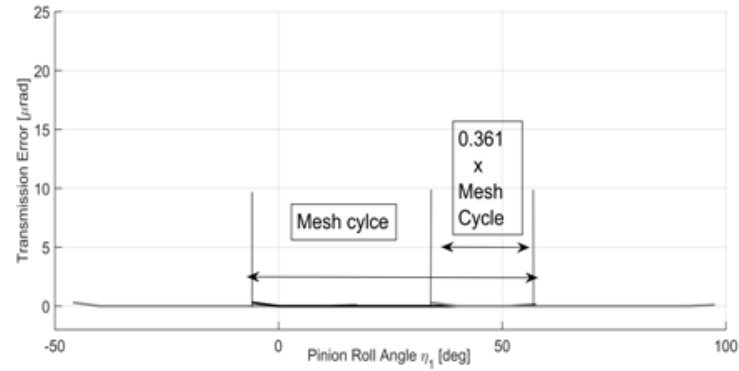

(b) Shaft Offset $\mathrm{E}=0.00055 \mathrm{~mm}$.

Fig. 16: Unloaded transmission error based on the gear pair generated using data of Table 2.

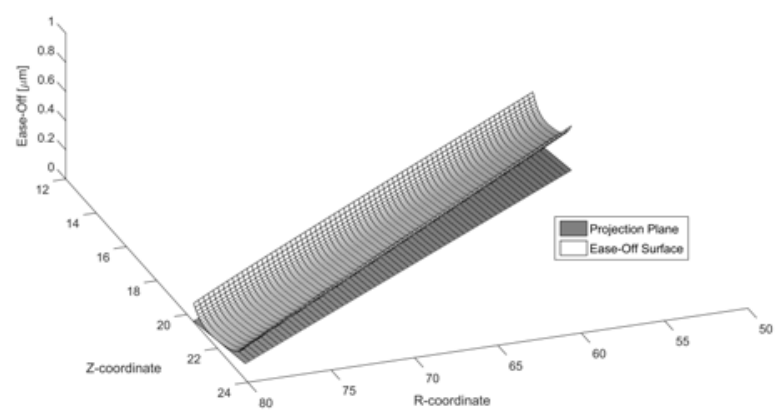

(a) Shaft Offset $\mathrm{E}=0.0 \mathrm{~mm}$.

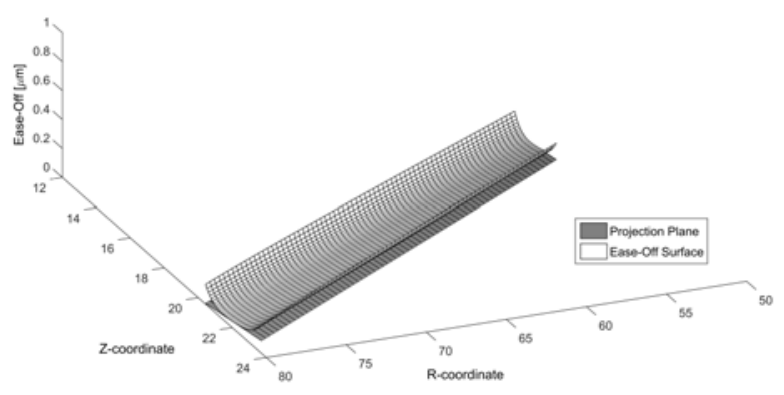

(b) Shaft Offset $\mathrm{E}=0.00055 \mathrm{~mm}$.

Fig. 17: Ease-off topography for the gear pair generated using data from Table 2.

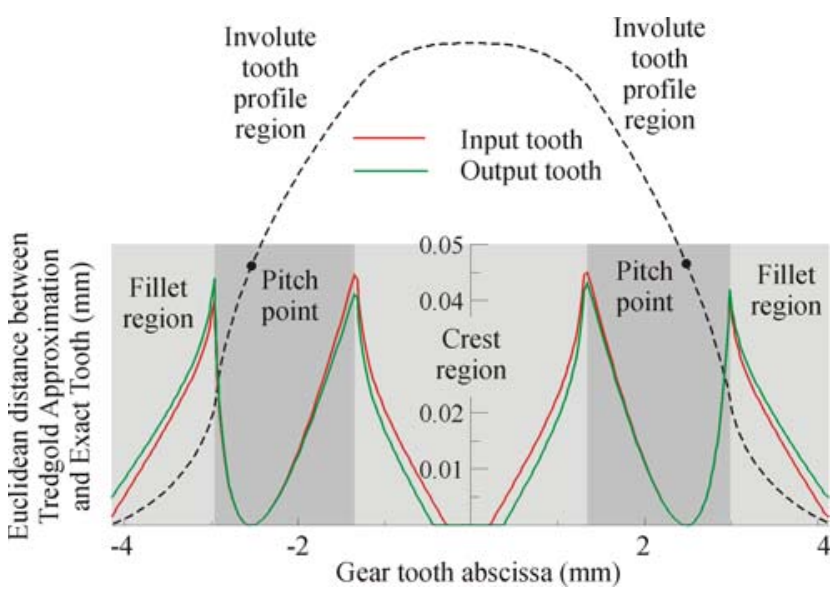

Fig. 18: Euclidean distance between Tredgold's Approximation and Exact tooth profile. 


\section{Summary}

To the authors' awareness, presented is the first procedure to directly specify conjugate teeth for spatial gear elements (viz., spiral bevel and hypoid gears) in a fashion akin to the specification of spur and helical gears. This procedure is applicable for any gear tooth (viz., involute, cycloid, and circular-arc) and gear type (viz., spur, helical, spiral bevel, hypoid, and non-circular gears). This procedure extends the existing Tredgold's Approximation and enables fully conjugate gear teeth to be specified using a planar gear tooth profile. Such a process can lead to inter-changeability between mating gear elements for spiral bevel and hypoid gear pairs. Further, a procedure for determining unloaded transmission error is presented. With the purpose of validating the proposed procedure for extending Tredgold's Approximation, an ease-off topography based methodology for unloaded tooth contact was implemented. The correctness of the unloaded tooth contact procedure has been validated using a face-milled spiral bevel gear pair, for which the data was taken from literature. Using the methodology, developed in the first part of the paper, a gear pair, similar to the one from literature, has been created and analyzed using the unloaded tooth contact model. These results have been shown as an illustrative example of the procedure for calculating conjugate teeth for spatial elements. Zero value unloaded transmission error results for the spiral bevel gear set, showing the validity of the presented methodology.

\section{Acknowledgement}

The second author of this paper is currently enrolled in a dual PhD programme the Katholieke Universiteit of Leuven (Belgium) and at the University of Calabria (Italy), supported by the People Programme (Marie Curie Actions) of the 7th Framework Programme of the European Union FP7/2007-2013, under the contract with the Research Executive Agency (REA) n. 324336 and the related research project DEMETRA - "Design of Mechanical Transmissions: Efficiency, Noise and Durability Optimization” (www.fp7demetra.eu). Part of this work was developed at Siemens Industry Software in Leuven (Belgium), industrial partner of the DEMETRA project. Professor Wim Desmet, from the Katholieke Universiteit of Leuven and Dr. Gert Heirman, from Siemens Industry Software, are gratefully acknowledged for their support.

\section{References}

[1] Radzevich, S.P., 2013, Theory of Gearing, CRC Press, Taylor \& Francis Group, Boca Raton

[2] Figliolini G. and Angeles J., 2005, “Algorithms for Involute and Octoidal Bevel-Gear Generation”, ASME J. Mech. Design, 127(4), 664-672.

[3] Figliolini G., Stachel H., Angeles J., 2013. “On Martin Disteli's spatial cycloidal gearing,” Mechanism and Machine Theory, 60 (1), pp. 73-89

[4] Phillips, J.R., 2003, General Spatial Involute Gearing, Springer, Berlin, Germany.

[5] Figliolini, G., Stachel, H., Angeles, J., 2015. “A spatial version of octoidal gears via the generalized Camus theorem,” ASME J. of Mechanisms and Robotics, 8 (2), p. 021015-13.

[6] Dooner, D.B., 2012, Kinematic Geometry of Gearing, 2nd edition, Wiley. London.

[7] Kolivand, M., 2009. "Development of tooth contact and mechanical efficiency models for face-milled and face-hobbed hypoid and spiral bevel gears,” PhD thesis, Graduate School of The Ohio State University.

[8] Litvin, F.L., and Fuentes, A., 2004, Gear Geometry and Applied Theory, 2nd ed. Cambridge University Press, London England.

[9] Litvin, F., Fuentes, A., and Hayasaka, K., 2006. "Design, manufacture, stress analysis, and experimental tests of low-noise high endurance spiral bevel gears,” Mechanism and Machine Theory, 41, pp. 81-118.

[10] Kolivand, M., and Kahraman, A., 2009. "A load distribution model for hypoid gears using ease-off topography and shell theory,” Mechanism and Machine Theory, 44, pp. 1848-1865.

[11] Bär, G., and Liebschner, B., 1991 “Fitting Flanks and Contact Properties of Hypoid Gears,” 8th World Congress on the Theory of Machines and Mechanisms, Vol. 4. Prague, pp. 1095-1098.

[12] Kolivand, M., Li, S., and Kahraman, A., 2010. "Prediction of mechanical gear mesh efficiency of hypoid gear pairs," 
Mechanism and Machine Theory, 45, pp. 1568-1582.

[13] Park, D., Kolivand, M., and Kahraman, A., 2011, "Prediction of surface wear of hypoid gears using a semianalytical contact model,” Mechanism and Machine Theory, 52, pp. 180-194.

[14] Shih, Y., 2010. “A novel ease-off flank modification methodology for spiral bevel and hypoid gears,” Mechanism and Machine Theory, 45, pp. 1108-1124.

[15] Artoni, A., Gabiccini, M., and Kolivand, M., 2013, "Ease-off based compensation of tooth surface deviations for spiral bevel and hypoid gears: Only the pinion needs corrections,” Mechanism and Machine Theory, 61, pp. 84-101.

[16] Delgear, 2015, http:॥www.delgear.com.

[17] Buchanan, R., Practical Essays on Mill Work and Other Machinery, John Weale, Architectural Libraray, 59, High Holborn, London, 1841. Digitized by Google, G. Woodfall and Son, Angel Court, Skinner Steet London.

[18] Wikipedia, Thomas Tredgold, 2015, https://en.wikipedia.org/wiki/Thomas_Tredgold.

\section{Nomenclature}

$\phi \quad$ Nominal pressure angle

$\mathrm{r}_{\mathrm{c}} \quad$ Radius of planar tooth profile

$\mathrm{r}_{\mathrm{c}}^{\prime} \quad$ Derivative $\mathrm{r}_{\mathrm{c}}$ of wrt $\theta_{\mathrm{c}}$

$\theta_{\mathrm{c}} \quad$ Angular position of tooth profile

$\bar{\theta}_{\mathrm{c}} \quad$ Angle tooth normal intersect pitch circle

$u_{\mathrm{p}} \quad$ Throat radius of hyperboloidal pitch surface

$u_{\mathrm{pc}} \quad$ Radius of cutter pitch circle

$\bar{\phi}_{\mathrm{c}} \quad$ Instantaneous pressure angle

$\left(x_{\mathrm{c}}, y_{\mathrm{c}}\right) \quad$ Cartesian coordiantes of planar cuttter

$\left(\bar{x}_{\mathrm{c}}, \bar{y}_{\mathrm{c}}\right) \quad$ Cartesian coordinates of image $\left(x_{\mathrm{c}}, y_{\mathrm{c}}\right)$

$\Delta_{\mathrm{c}} \quad$ Distance between $\left(x_{\mathrm{c}}, y_{\mathrm{c}}\right)$ and $\left(\bar{x}_{\mathrm{c}}, \bar{y}_{\mathrm{c}}\right)$

$\kappa_{\max } \quad$ Maximum pitch surface curvature

$\kappa_{\min } \quad$ Minimum pitch surface curvature

$\kappa_{\mathrm{n}} \quad$ Normal pitch surface curvature

$\psi_{\mathrm{p}} \quad$ Pitch surface spiral angle

$v_{\mathrm{i}} \quad$ Angular position of gear element

$\alpha_{\mathrm{p}} \quad$ Generator angle of pitch surface

$\gamma_{\mathrm{p}} \quad$ Angle between generator and transverse curve

$w_{\mathrm{p}} \quad$ Axial position along generator

$\Gamma \quad$ Envelope of $\left(x_{\mathrm{c}}, y_{\mathrm{c}}\right)$

$\mathbb{S}_{\psi} \quad$ Spiral tangency

$\mathbf{N}_{\mathrm{p}} \quad$ Pitch surface normal

$\mathrm{C}_{\mathrm{p}} \quad$ Direction of pitch surface generator

$\mathbf{t}_{\mathrm{p}} \quad$ Point on pitch surface

$\mathbf{t}_{\mathrm{p}}^{\prime} \quad$ Tangency to transverse curve on pitch surface

$\underline{\$}_{l} \quad$ Line of action

$S_{1} \quad$ Pinion Reference Frame

$S_{2} \quad$ Gear Reference Frame

$S_{h} \quad$ Housing Reference Frame

$S_{2_{E}} \quad$ Reference Frame that includes shaft offset

$E \quad$ Shaft offset (Hypoid offset)

$\Sigma \quad$ Shaft angle

$\eta_{1} \quad$ Pinion roll angle

$\eta_{2} \quad$ Gear roll angle

$\mathbf{r}_{1}^{(1)} \quad$ Cartesian coordinate vector of a point on the pinion surface, in $S_{1}$

$\mathbf{N}_{1}^{(1)} \quad$ Surface normal at a point $P$ on pinion surface, in $S_{1}$

$\boldsymbol{\rho}_{h} \quad$ Cartesian coordinate position vector $\boldsymbol{\rho}_{h}=\mathbf{r}_{h}^{(1)}-\mathbf{E}_{h}$ that include the rotational moment, in $S_{h}$

$\mathbf{r}_{h}^{(1)} \quad$ Cartesian coordinate vector of a point on the pinion surface, in $S_{h}$ 


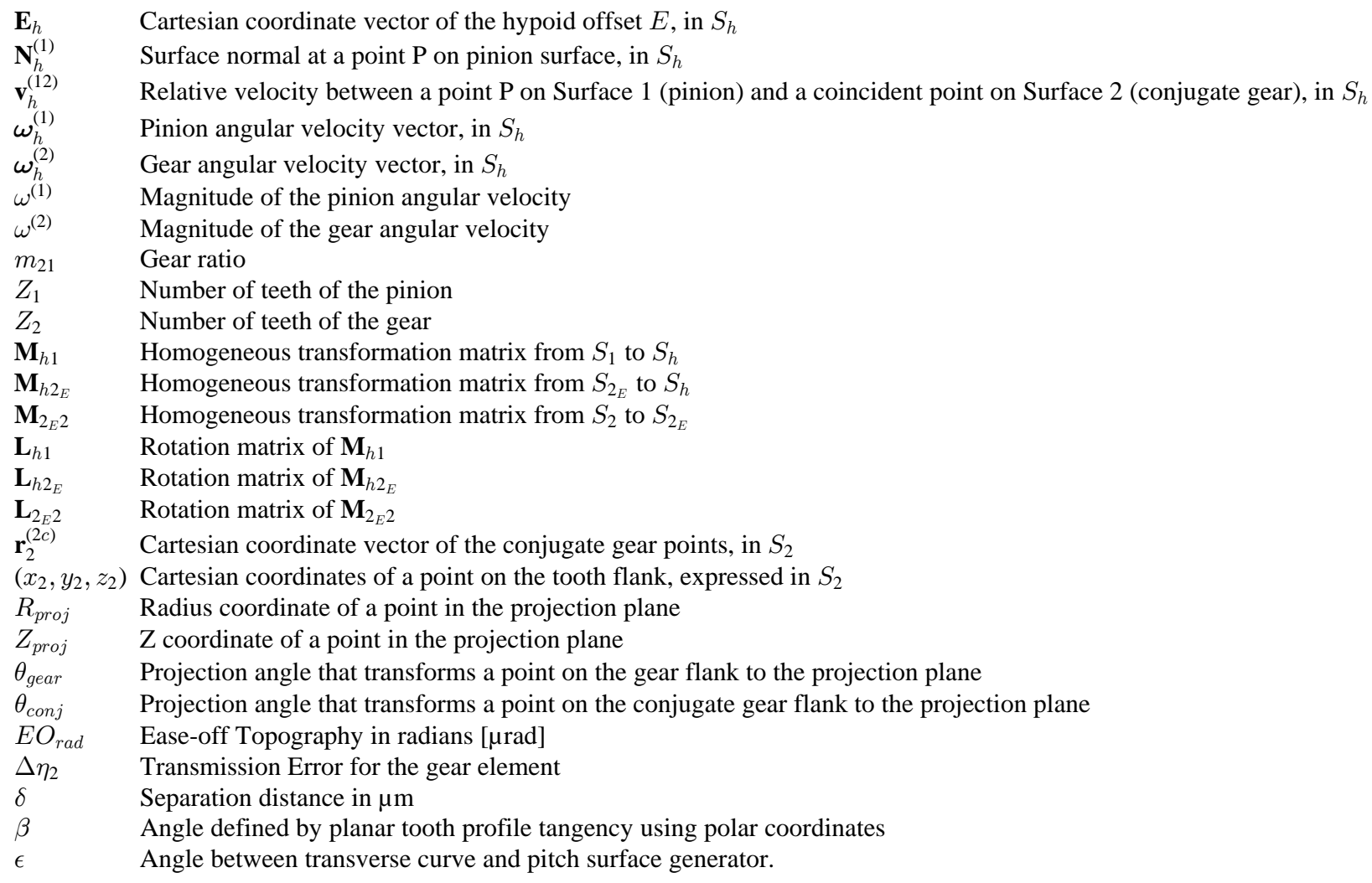

\section{Appendix: On the history of Tredgold's Approximation}

Tredgold's Approximation is simple with little attention focused on its development. This approximation is presented below as originally quoted [17].

... To these a third may by added, that is, When the pinion drives the wheel, the most advantageous form for the acting faces of the

teeth of the pinion, will be a spherical involute of a circle, the teeth of the wheel being plane surfaces directed to its axis.

The description of these curves is not a very simple operation, nor yet adapted for application, in practice; I shall therefore

propose a new method, which appears to have escaped the notice of former inquirers, one which is general; spur wheels, racks, \&c.

being particular cases of its application. (Fig. E p. 103 --2nd ed., See Fig. E, p. 59.--3rd ed.)

Depicted in Fig. 19 is Fig. E from the third edition of Practical Essays on Mill Work and Other Machinery.

Tredgold's approximation is so pervasive most texts state its relation and few texts acknowledge an origin. Thomas Tredgold was apprenticed as a cabinet maker in his youth, later studied architecture and engineering on his own, and practiced civil engineering [18]. He is noted as an English railway engineer and writer. His books include Elementary Principles of Carpentry (1820), A Practical Essay on the Strength of Cast Iron and other Metals (1822), Principles of Warming and Ventilating Public Building (1824), A Practical Treatise on Railroads and Carriages (1825), and The Steam Engine (1827). It is Robertson Buchanan's book Practical Essays on Mill Work and Other Machinery where the widely referenced Tredgold's approximation is traced [17].

Three editions of Practical Essays on Mill Work and Other Machinery exist: a first edition in 1808, a second edition in 1832, and a third edition in 1841. Tredgold is not referenced in the first edition whereas the second and third edition state

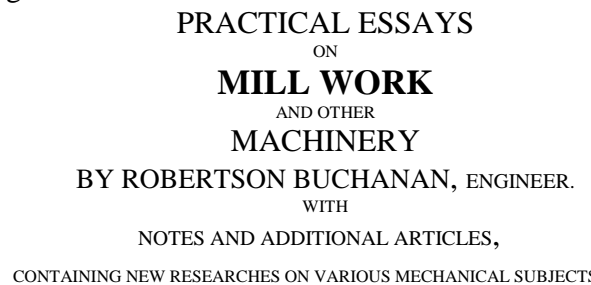

BY THOMAS TREDGOLD, C.E.,

Searching the Table of Contents, we have

MEMBER OF THE INSTITUTION OF CIVIL ENGINEERS.

Sect. II.—Of bevel geer, art. 41.— [D. 43.] - 89 
* New principle of describing the teeth of bevelled wheels - - 99

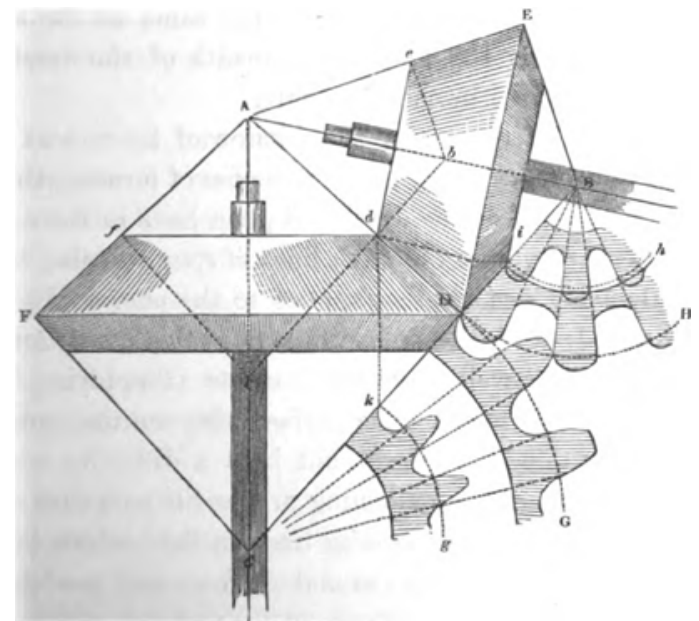

Fig. 19. (Fig E from 2nd and 3rd editions).

Again, Fig. E of Fig. 19 is not part of Buchanan's 1808 first edition of Practical Essays on Mill Work and Other Machinery. Fig. $\mathrm{E}$ is presented in Section "[A. 43]" of the second edition and Section "58" in the third edition. The preface to the third edition included the preface to the first edition with the below comment at the end of the preface:

Note.-The Second Edition was superintended by the late Mr. Tredgold; and the principal facts noticed in it are incorporated in the following Preface.

No doubt new matter on bevel gearing is presented in the second and third editions; namely, Tredgold's approximation. Additionally, Buchanan authored An Essay on Warming of Mills, and Buildings, by Steam (1807). It is clear that Tredgold and Buchanan worked together with intersecting interests. Moreover, both the second and third editions of Practical Essays on Mill Work and Other Machinery were published posthumously; Buchanan died in 1816 at age 47 and Tredgold died in 1829 at age 40.

There is no direct indication that Tredgold authored this new matter. It is possible that Tredgold is the originator of Tredgold's approximation. It is also possible Tredgold used Buchanan's relation for bevel gears to estimate tooth strength as Tredgold demonstrated interest in "strength". Buchanan was interested in kinematics of gear teeth as the first chapter of this book is titled "On the Teeth of Wheels" and Buchanan had studied the works of De la Hire, Euler, and others. Perhaps the biggest reason for the Tredgold credit is due to Robert Willis (1800-1875) where in his book Principles of Mechanism (1870) he states

Now by developing these conical tangent surfaces into planes we obtain a practical mode of describing the teeth, which was first suggested by Tredgold. $\dagger$

where the footnote $\dagger$ is

† Buchanan's Practical Essays on Mill-work, by Tredgold, 1832, p. 103; or new ed. 1841, p. 59.

Willis writes below in the Preface of his first edition (1841):

These works being so well known I have not so constantly referred to my authorities in this chapter, but it will be found that I have incorporated into it extracts from the valuable paper of Professor Airy, as well as the entire contents of my own paper from the Transactions of the Society of Civil Engineers, and have added several original investigations relating to the proportions of the teeth, and their least numbers. Some of these questions have been discussed by Kaestner*, but not in a manner adapted to practice. Tredgold has also given some results*, but has unfortunately vitiated them by the coarseness of his approximations. It will be found that I have calculated all the results that are required in practice, and have arranged them in tables for reference.

where the footnote * is

* Vide Buchanan's Essay.

Willis was 16 years old when Buchanan died and 29 years old when Tredgold died. It possible that Willis knew and worked with Tredgold and Tredgold is properly credited. 